\title{
Differences in Clinical Nature and Outcome Among Young Patients Suffering from an Acute Coronary Syndrome
}

\author{
Mohammad Saeed \\ Al-Shahrani (iD) ${ }^{1,2}$ \\ Faisal Ahmad Katbi ${ }^{1,2}$ \\ Abdulaziz Mohammad \\ Al-Sharydah iD $^{3}$ \\ Saad Dhafer AIShahrani ${ }^{4}$ \\ Talal Mosfer Alghamdi (D) ${ }^{5}$ \\ Mohammad Adnan \\ Al-Sharidah' \\ 'Department of Emergency, King Fahd \\ Hospital of the University, Imam \\ Abdulrahman Bin Faisal University, \\ Khobar City, Eastern Province, Saudi \\ Arabia; ${ }^{2}$ Department of Critical Care, \\ King Fahd Hospital of the University, \\ Imam Abdulrahman Bin Faisal University, \\ Khobar City, Eastern Province, Saudi \\ Arabia; ${ }^{3}$ Department of Diagnostic and \\ Interventional Radiology, King Fahd \\ Hospital of the University, Imam \\ Abdulrahman Bin Faisal University, \\ Khobar City, Eastern Province, Saudi \\ Arabia; ${ }^{4}$ Department of Emergency, Royal \\ Commission Hospital, Jubail City, Eastern \\ Province, Saudi Arabia; ${ }^{5}$ Department of \\ Anesthesia, King Fahd Hospital of the \\ University, Imam Abdulrahman Bin Faisal \\ University, Khobar City, Eastern \\ Province, Saudi Arabia
}

Purpose: Acute coronary syndrome (ACS) is a life-threatening cardiac disease identified by acute, regional reductions in coronary blood flow, resulting in myocardial ischemia, or infarction, and manifesting as discomfort in the chest area, neck, or arms. Frequently, ACS is provoked by an atherosclerotic plaque; therefore, coronary atherosclerosis is converted into a chronic disease to an acute medical emergency. The purpose of this study was to explore the differences among these variables in patients less than 45 years of age suffering from this major health problem compared to older adults admitted with an ACS diagnosis, and to adopt an optimized temporary management.

Patients and Methods: A retrospective chart review study was conducted on a total of 652 ACS patients admitted at King Fahad Hospital of the University (KFHU) between 2015 and 2020. The patients' medical records were utilized for obtaining demographic data, presenting symptoms, risk factors, and clinical outcomes.

Results: Overall, 652 patients were enrolled. Of these, 109 patients $(16.7 \%)$ were under 45 , with a mean age of $38 \pm 7$. Younger patients showed a higher rate of palpitation (23.9\% versus. $13.6 \%$; $\mathrm{P}=0.019$ ). A positive smoking history and a family history of CAD were seen more often in younger patients $(42.2 \%$ vs $27.3 \%, \mathrm{P}<0.001 ; 22.9 \%$ vs $9.4 \%, \mathrm{P}<0.001$, respectively). Older patients had greater renal impairment with higher creatinine (median $=1.10 \mathrm{mg} / \mathrm{dl}$ (range, $0.3-$ 13.0) vs $1.0(0.3-19.0 ; \mathrm{p}=0.001)$, BUN (median = 16.0 (mange, 0.9-141.0) vs $12.0(0.9-49.0)$; $\mathrm{P}<0.001)$ ). Younger patients had higher levels of LDL and total cholesterol (median 138c. 115; $\mathrm{p}<0.001$ ) and cholesterol (median 209 vs 178.5; $\mathrm{p}<0.001$ ). Hospital mortality was $0.9 \%$ in younger patients versus $7.4 \%$ in older patients $(\mathrm{P}=0.004)$.

Conclusion: Palpitations, smoking, family history, higher LDL levels, and total cholesterol levels were more prevalent in adults younger than 45 years old with ACS. Impaired renal function, hypertension, and diabetes were more in older patients with ACS.

Keywords: acute coronary syndrome, young adults, clinical features, in-hospital outcome

\section{Introduction}

Cardiovascular disease, which includes coronary heart disease and stroke, is the leading cause of death and disease burden globally. ${ }^{1}$ Acute coronary syndrome (ACS) is characterized by acute local reduction in blood flow to the myocardium, also known as ischemia. ${ }^{2}$ Ischemic heart disease may present with a variety of symptoms, eg, a symptom complex called acute coronary syndrome (ACS), which may lead to a diagnosis of one of unstable angina (UA), non-ST-segment elevation myocardial infarction (NSTEMI), or ST-segment elevation myocardial infarction
Correspondence: Mohammad Saeed Al-Shahrani

Email msshahrani@iau.edu.sa 
(STEMI). The former is a clinical diagnosis, whereas the latter two are diagnosed from the abnormalities seen on the EKG, possibly complemented by serum enzyme assays, eg, of troponin $\mathrm{C}^{3}$

Atherosclerosis is a chronic inflammatory process of the arterial wall, and although it starts early in life, it takes years to be of serious pathological severity, so that young people do not present with ACS very often. ${ }^{4,5}$ However, in recent years, coronary artery disease (CAD) has been affecting younger patients, which raises concern due to the accompanying results of premature morbidity and mortality. ${ }^{5}$ Patients less than 45 years of age represent $6-10 \%$ of cardiac infarctions in the United States. ${ }^{5-7}$ Smoking was found to be the prevailing risk factor and was frequently found along with coronary events in young patients. ${ }^{8,9}$ ACS presents with similar clinical features irrespective of age 9 The main presenting symptom is chest pain in both the young as well as in the elderly. ${ }^{10}$ It is also important to note that the severity and presentation of the diseases caused by atherosclerosis seem to differ between men and women in their different stages of life. ${ }^{11}$ For example, men are more likely to develop advanced coronary artery disease (CAD) compared to pre-menopausal women. ${ }^{12}$ However, postmenopausal women are more affected by an adverse prognosis than their male counterparts. ${ }^{12}$

Publications on ACS from Saudi Arabia are limited and there is a definite paucity of new information about the increasing prevalence among young patients less than 45 years of age. ${ }^{13}$ We hypothesized that the clinical severity and outcomes of ACS patients are different for young people compared to older patients, owing to their different lifestyles and cultural differences. The aim of this present study was to explore the demographic characteristics, cardiovascular risk factors, short-term outcomes and complications in young adults below the age of 45 years compared to older adults who were admitted with a diagnosis of ACS at the King Fahd University Hospital between 2015 and 2020, in order to update the expertise on this major health problem. This study complements the scarce existing data on the acute coronary syndrome in youth and adults and is considered helpful for resource planning and short-term management optimization.

\section{Materials and Methods}

\section{Setting}

The study was conducted at King Fahad Hospital of the University (KFHU), a tertiary care university teaching hospital with 600 beds in the Eastern Province of Saudi Arabia. It is a retrospective study that was conducted using medical records of all ACS patients admitted between 2015 and 2020. Demographic data, presenting symptoms, risk factors, and clinical outcomes were obtained. The local institutional research body approved this study.

\section{Study Design and Study Population}

A descriptive retrospective study was conducted with the sample size determined by the number of patients in King Fahd Hospital of the University in Al-Khobar city, and this was a total of 652 patients. All methods were performed in accordance with STROBE guidelines and regulations of cohort studies.

\section{Inclusion and Exclusion Criteria}

We recruited all patients who were diagnosed with ACS based on the international classification of diseases version 10 ICD-10, including younger adult patients (from 18 to 45 years old) and older patients (above 45-year-old). We excluded patients labeled DNR (do not resuscitate), and incomplete patient files (48 patients).

\section{Statistical Analysis}

All categorical variables were represented by frequency as percentages, and were analyzed using chi-squared and Fisher's exact tests. Continuous variables were represented by median with range because the data did not follow the normal distribution. The Mann-Whitney $U$-test was used for the comparison between the two groups. All analyses were performed using SPSS (21 version). A P value of less than 0.05 was considered significant by Kruskal-Wallis test.

\section{Ethical Approval}

This study was performed in accordance with the Helsinki Declaration of 1975 (revised in 1983) and the Imam Abdulrahman Bin Faisal University Institutional Review Board considered the descriptive and retrospective nature of this study and granted approval for the study to be conducted at KFHU (IRB-UGS-2016-01-075). Anonymized data were collected, analyzed, and reported only in aggregate form, and no identifiable participant information (image, face, name, etc.) was revealed in the study.

\section{Results}

A total of 652 patients were enrolled in this study without significant difference in gender distribution (M:F, 1:1) (Figure 1). Of these, 109 (16.7\%) patients were less than 


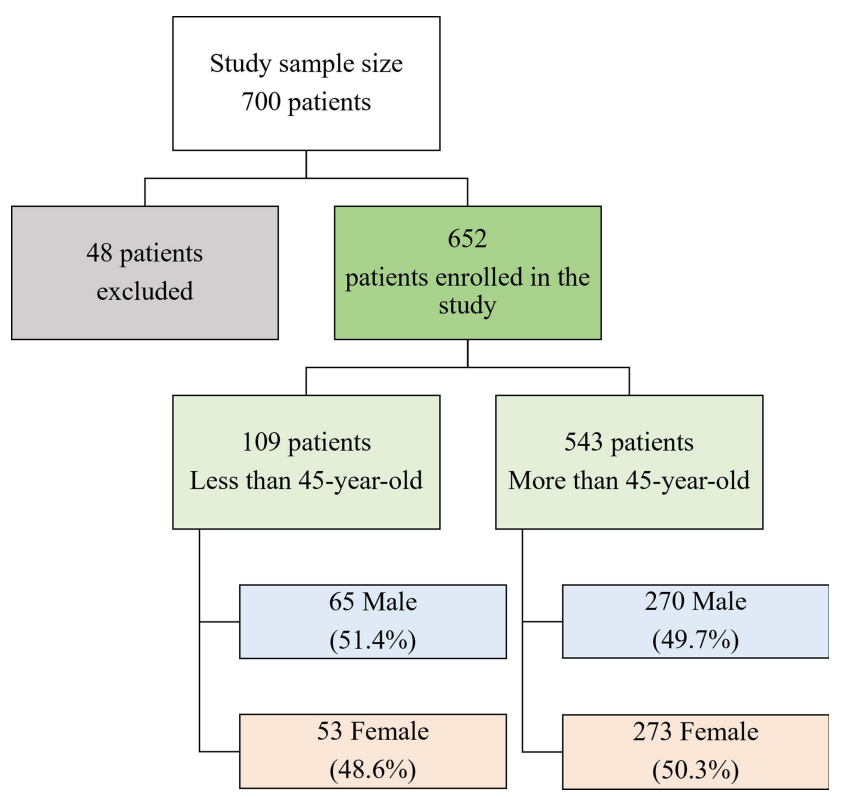

Figure I Flowchart illustrating the inclusion and exclusion criteria for the study and the size of the patient groups.

45 years of age. The mean age was $38 \pm 7$ vs $60 \pm 11$ years in the young and old groups, respectively $(\mathrm{P}<0.001)$. Table 1 shows that younger patients had a higher frequency of palpitations $(23.9 \%$ vs $13.6 \%$; $\mathrm{P}=0.019)$. Older patients had higher frequencies of hypertension, eg, a systolic blood pressure reading of $>140 \mathrm{mmHg}$ (68.7\% vs $37.6 \%$; $\mathrm{P}<0.001)$, diabetes $(61.1 \%$ vs $37.6 \%$, $\mathrm{P}<0.001)$, and history of CAD $(52.3 \%$ vs $30.3 \%$; $\mathrm{P}<$ 0.001 ), but less frequent history of smoking, and positive family history, which were higher among younger patients

Table I Clinical Presentations of ACS Upon Admission According to Age

\begin{tabular}{|l|l|l|l|}
\hline Presentation & $\begin{array}{l}\text { Less Than 45- } \\
\text { Year-Old } \\
(\mathbf{n}=109)\end{array}$ & $\begin{array}{l}\text { More Than 45- } \\
\text { Year-OId } \\
(\mathbf{n}=543)\end{array}$ & P value* \\
\hline $\begin{array}{l}\text { Chest pain } \\
\text { Epigastric pain }\end{array}$ & $97(89 \%)$ & $444(81.8 \%)$ & $0.07 I^{* *}$ \\
Syncope/ Pre- & $11(10.1 \%)$ & $60(11 \%)$ & 0.929 \\
Syncope & $48.2 \%)$ & $48.8 \%)$ & 0.834 \\
Dyspnea/ SOB & $49(45 \%)$ & $243(44.8 \%)$ & 0.286 \\
Palpitation & $26(23.9 \%)$ & $74(13.6 \%)$ & $0.019 * *$ \\
Sweating & $38(34.9 \%)$ & $185(34.1 \%)$ & 0.604 \\
Nausea and & $29(26.6 \%)$ & $126(23.2 \%)$ & 0.446 \\
vomiting & & $38(7 \%)$ & 0.246 \\
Cardiac arrest & $3(2.8 \%)$ & 38 & \\
\hline
\end{tabular}

Notes: *Statistical significance was set at $\mathrm{p}$-values $<0.05$. **Statistically significant by Kruskal-Wallis test.

Abbreviations: SOB, Shortness of breath; $n$, total number of patients.
Table 2 Risk Factors of ACS Patients According to Age

\begin{tabular}{|c|c|c|c|}
\hline Risk Factor & $\begin{array}{l}\text { Less Than } 45- \\
\text { Year-Old } \\
(n=109)\end{array}$ & $\begin{array}{l}\text { More Than 45- } \\
\text { Year-Old } \\
(n=543)\end{array}$ & P value* \\
\hline HTN & $4 \mid(37.6 \%)$ & $373(68.7 \%)$ & $<0.001 * *$ \\
\hline DM & $4 \mathrm{I}(37.6 \%)$ & 332 (61.1\%) & $<0.001 * *$ \\
\hline $\begin{array}{l}\text { Abnormal lipid } \\
\text { profile }\end{array}$ & $60(55.0 \%)$ & 227 (4I.8\%) & 0.038 \\
\hline Smoking history & 46 (42.2\%) & I 48 (27.3\%) & $<0.001 * *$ \\
\hline Family history & 25 (22.9\%) & 51 (9.4\%) & $<0.001 * *$ \\
\hline CAD history & 33 (30.3\%) & 284 (52.3\%) & $<0.001 * *$ \\
\hline
\end{tabular}

Notes: *Statistical significance was set at $\mathrm{p}$-values $<0.05$. **Statistically significant by Kruskal-Wallis test.

Abbreviations: HTN, Hypertension; DM, Diabetes Mellitus; $n$, total number of patients.

(42.2\% vs $27.3 \%, \mathrm{P}<0.001,22.9 \%$ vs $9.4 \% ; \mathrm{P}<0.001)$ (Table 2).

Table 3 shows the laboratory outcomes; older patients had significantly higher creatinine levels (median $=1.10 \mathrm{mg}$ / dl (range, 0.3-13.0) vs $1.0(0.3-19.0) ; \mathrm{p}=0.001)$, BUN $($ Median $=16.0$ (Range, $0.9-141.0)$ vs $12.0(0.9-49.0) ; \mathrm{P}<$ 0.001), but less in $\mathrm{Hb}$, LDL cholesterol and total cholesterol, which were high among younger patients $(14.4 \mathrm{~g} / \mathrm{dl}(8.4$ 17.6) vs $13.5 \mathrm{~g} / \mathrm{dl}(0.11-158) ; \mathrm{P}<0.001,138 \mathrm{mg} / \mathrm{dl}$ (43-224) vs $115 \mathrm{mg} / \mathrm{dl}(25-411) ; \mathrm{p}<0.001,209 \mathrm{mg} / \mathrm{dl}(59-303)$ vs $178.5 \mathrm{mg} / \mathrm{dl}(18-485) ; \mathrm{p}<0.001)$ (Figure 2).

Table 4 shows the length of hospital admission and mortality, and there was a significant difference in mortality, that is, the in-hospital mortality was $7.4 \%$ among older patients and $0.9 \%$ among younger patients $(\mathrm{P}=0.004)$.

\section{Discussion}

Acute coronary syndrome (ACS) in young adults is a rare entity, yet it occurs. Assessing the clinical features, risk factors, and outcomes, which may be due to either primary disease or secondary complications, would set several measures to prevent further episodes of ACS. In this study, our cutoff point to define young patients was 45 years. It was determined upon similar studies in Thailand, Singapore, Israel, and California. ${ }^{14,15}$ While other studies from Japan, Poland, Germany, Australia, New Zealand, and the USA have defined young adults to be under 40 years. ${ }^{15}$ Our findings are as follows: First, 109 ACS patients were younger than 45 years with a mean age of $38 \pm 7$. Domestic and international studies found that $5-$ $10 \%$ of ACS manifest before the age of $46 .^{16,17}$

Our estimated prevalence was slightly higher than the reported percentages. The authors attributed the increased 
Table 3 Comparison of Laboratory Work Up Results in ACS Patients According to Age

\begin{tabular}{|c|c|c|c|}
\hline Lab. Result & $\begin{array}{l}\text { Less Than } 45 \text {-Year-Old }(n=109) \text { (Median, } \\
\text { Average) }\end{array}$ & $\begin{array}{l}\text { More Than 45-Year-Old }(n=543) \text { (Median, } \\
\text { Average) }\end{array}$ & P value* \\
\hline Creatinine $(\mathrm{mg} / \mathrm{dL})$ & I $(0.3-19)$ & I.I $(0.3-13.0)$ & $0.00 I^{* *}$ \\
\hline BUN (mg/dL) & $12(0.9-49.0)$ & $16(0.9-141.0)$ & $<0.00 I^{* *}$ \\
\hline Hemoglobin $(\mathrm{g} / \mathrm{dL})$ & I4.4 (8.4-17.6) & $13.5(0.1 \mid-158)$ & $<0.00 I^{* *}$ \\
\hline Troponin (ng/mL) & I.63 (0.04-450) & $1.08(0.01-165.5)$ & 0.286 \\
\hline LDL (mg/dL) & $138(43-224)$ & $1 \mid 5(25-4 I I)$ & $<0.00 I^{* *}$ \\
\hline $\mathrm{HDL}(\mathrm{mg} / \mathrm{dL})$ & $36(10-56.0)$ & $36(9-172.0)$ & 0.283 \\
\hline Triglyceride (mg/dL) & $139(20-1|| \mid)$ & $126(1.18-557.0)$ & 0.103 \\
\hline Total Cholesterol (mg/dL) & $209(59-303)$ & $178.5(18-485)$ & $<0.001 * *$ \\
\hline
\end{tabular}

Notes: *Statistical significance was set at $\mathrm{p}$-values $<0.05$. **Statistically significant by Kruskal-Wallis test.

Abbreviations: $n$, total number of patients; lab., laboratory; ACS, acute chest syndrome; BUN, blood urea nitrogen; LDL, low-density lipoproteins; HDL, high-density lipoproteins; g, gram; mg, milligram; dL, deciliter; mL, milliliter.

ACS exposure to health system's transformation and adopting western lifestyle as a new way of living in Saudi Arabia as risk factors. Second, regarding risk factors, older patients had a higher frequency of hypertension, diabetes, and a history of CAD. Also, Systemic Mastocytosis (SM) is proven to be a major risk factor for developing acute coronary syndrome. ${ }^{18}$ However, unlike younger patients, they had less frequent history of smoking and family history of ACS. Furthermore, a recent retrospective cohort study of two academic institutions suggests an increased likelihood of encountering ACS with a family history of hypercholesterolemia. ${ }^{19}$ Previous studies reported that $82 \%$ of young patients who suffered from ACS were smokers which makes smoking a crucial risk factor. ${ }^{20-22}$ Chua et al interestingly found that the rate of smoking patients aged $\leq 35$ years who suffered from MI was significantly higher than in patients $>65$ years of age with the same condition. ${ }^{21}$

Aligning with the findings of other studies, it is suggested that both history of smoking and family cardiovascular disease are risk factors in young patients with ACS (Figure 2). ${ }^{20-22}$ A study in Thailand reached the same conclusion, whereas it discovered that the most common risk factor of ACS in patients aged $<45$ years of age was
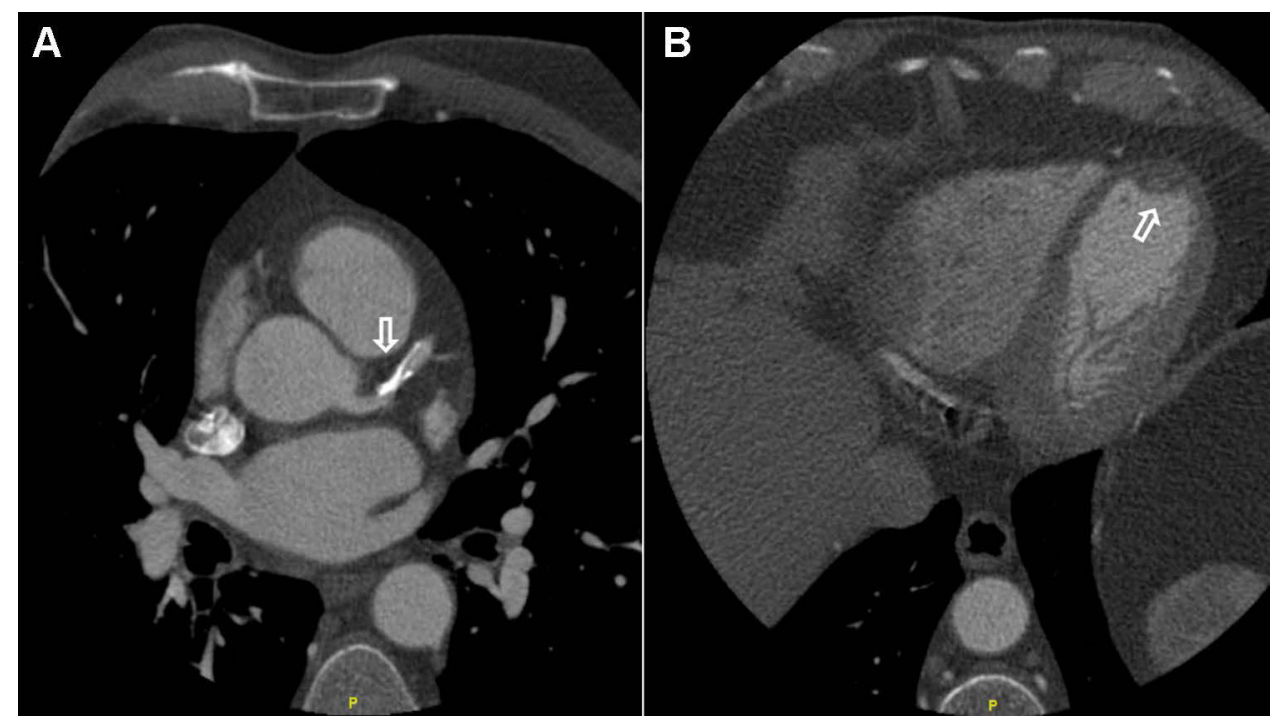

Figure 2 The patient is 42 years old, suffering from atypical chest pain. He's overweight, and his lab results came back positive for dyslipidemia. Cardiac CT scan performed to evaluate the presence of coronary heart disease. An ECG-gated cardiac CT acquisition was performed using an ECG-modulated radiation dose. A sublingual nitroglycerin tablet given three minutes prior to the procedure. (A) The left anterior descending artery presents a benign diffuse disease with moderate calcification and no apparent obstructive lesions (arrow). However, the presence of calcification impedes an accurate evaluation of stenosis. (B) The left ventricle is slightly dilated, the left ventricular volume at the end of diastolic is $211 \mathrm{~mL}$, and the volume at the end of systole is $114 \mathrm{~mL}$. The calculated ejector fraction is $46 \%$. An organized small wall-mounted apical clot was displayed (arrow), which denotes an infarction of the old LAD territory with an organized old LV apical clot. There is an akinese of the medium and distal septum and the major part of the apex (not shown). 
Table 4 In-Hospital Outcome for ACS Patients According to Age

\begin{tabular}{|l|l|l|l|}
\hline Outcome & $\begin{array}{l}\text { Less Than 45-Year- } \\
\text { Old (n= 109) } \\
\text { (Median, Average) }\end{array}$ & $\begin{array}{l}\text { More Than 45-s } \\
(\mathbf{n = 5 4 3 )} \\
\text { (Median, Average) }\end{array}$ & P value* \\
\hline $\begin{array}{l}\text { In-hospital } \\
\text { stay (days) } \\
\text { Mortality }\end{array}$ & $5(0-97)$ & $5(0-26)$ & 0.709 \\
\hline
\end{tabular}

Notes: *Statistical significance was set at $\mathrm{p}$-values $<0.05$. **Statistically significant by Kruskal-Wallis test.

Abbreviations: $n$, total number of patients; ACS, acute chest syndrome.

smoking. ${ }^{14}$ A different study found that patients whose parents developed cardiovascular disease of early onset had an increased risk of cardiovascular disease. ${ }^{23}$

Both quantity and duration of smoking accelerate the development of atherogenic cardiovascular disease. ${ }^{24,25}$ Furthermore, smoking also alters the defensive response of the immune system against vascular damage, which is characterized by an increase in oxidative influence on lipid peroxidation, endothelial cell dysfunction, and generation of foam cells in the tunica media. ${ }^{25,26}$ It also leads to increased platelet aggregation, disrupts the metabolic activities of lipoproteins, and tends to reduce HDL cholesterol. ${ }^{25,26}$ Cigarette smoking is linked to increased levels of inflammatory markers. During the acute phase of the inflammatory process, C-reactive protein is elevated, white blood cells and fibrinogen are increased, and serum albumin is decreased. ${ }^{24-26}$ Smoking can also increase myocardial load due to stimulation by catecholamines and reduce consumption of $\mathrm{O} 2$ due to inhalation of carbon monoxide, which may cause tachycardia, vasoconstriction of blood vessels, and which may modify the permeability of the vessel wall. ${ }^{25,26}$

Primary and secondary prevention specifically are important in this subset of patients. In addition, one study has shown that diabetes mellitus was more prevalent in younger adults. Emphasized by several authors, ACS is clinically similar in both young patients and the elderly. ${ }^{9,27-29}$ However, in our study, we found that palpitations occurred more frequently in younger adults.

In addition, some laboratory parameters including creatinine, and BUN, were higher in older patients, but HGB, LDL, and cholesterol levels were higher among younger patients. This result was similar to those of previous studies.

In our study, the length of stay was not significantly different between the two age groups, although other studies have shown that older patients with ACS had longer hospital stays. ${ }^{30,31}$ Besides, in-hospital mortality was $7.4 \%$ among older patients and $0.9 \%$ among younger patients.
Patients who were discharged from the hospital were followed by general cardiologists in an outpatient setting after an average of one month and then every year. Our findings align with those of a recent cohort of Yang et al, which demonstrated equity among both age groups in terms of short- and long-term outcomes. ${ }^{32}$

This study confirmed a previously established correlation between the modifiable risk factors of ACS, and adoption of healthy dietary habits and exercise programs. ${ }^{29,32}$ Compared to the western diet, changing nutritional behaviors and seeking weight reduction and reducing BMI strategies in patients with $\mathrm{CAD}$ and metabolic syndrome found to show significant improvement in patients' inflammatory and metabolic biomarkers. ${ }^{33}$ This current study is newly conducted by licensed academic physicians from various medical specialties involved in the management of ACS including emergency medicine, vascular interventional radiology, anesthesiology, and intensive care medicine with adequate experience in ACS management, in a teaching hospital. Similar national and international studies have only examined the relationship of ACS to sex and age - young or old. In contrast, our study examined the influence of all these determinants and their contribution to the clinical severity and outcomes in patients with ACS. Potential limitations of our study include the fact that our selected design was retrospective. However, our sample size was reasonably large (652 cases), which in our opinion reduced information bias and therefore strengthened the results. We accept the limitation of not to imploy the types of ACS in this study which might be a trigger for future studies. The changes in waist circumference which were reported to be linked to increased risk of ACS especially with waist circumference $\geq 102 \mathrm{~cm}$ in males and $\geq 88 \mathrm{~cm}$ in females were not included in our data collection. ${ }^{33}$

\section{Conclusion}

Palpitations, positive smoking history, positive family history, and higher lipid profile were more prevalent in adults younger than 45 years old with ACS than in older ones.

Impaired renal function, hypertension, and diabetes were more common in older patients with ACS. Younger patients seem to have a better outcome in terms of mortality with no difference in length of hospital stay.

\section{Abbreviations}

ACS, acute coronary syndrome; CAD, coronary artery disease; NSTEMI, non-ST-segment elevation myocardial infarction; STEMI, ST-segment elevation myocardial infarction. 


\section{Data Sharing Statement}

The datasets generated during and analysed during the current study are not publicly available due to the privacy of research participants but are available from the corresponding author on reasonable request.

\section{Consent to Participate}

Written informed consent was obtained from the patient. The Standing Committee for Research Ethics on Living Creatures (SCRELC) from the Imam Abdulrahman Bin Faisal University, Dammam, Saudi Arabia approved this project by IRB number: IRB-UGS-2016-01-075. No patients were involved neither in the design, recruitment and conduct of this study, nor in the development of outcome measures.

\section{Acknowledgments}

We wish to acknowledge the King Fahd Hospital of the University administrators and staff for providing much needed assistance throughout the course of this research.

\section{Author Contributions}

All authors made a significant contribution to the work reported, whether that is in the conception, study design, execution, acquisition of data, analysis and interpretation, or in all these areas; took part in drafting, revising or critically reviewing the article; gave final approval of the version to be published; have agreed on the journal to which the article has been submitted; and agree to be accountable for all aspects of the work.

\section{Funding}

This study did not receive any specific grant from funding agencies in the public, commercial, and not-for-profit sectors.

\section{Disclosure}

The authors declare no conflicts of interest for this work.

\section{References}

1. Redfern J, Hyun K, Chew DP, et al. Prescription of secondary prevention medications, lifestyle advice, and referral to rehabilitation among acute coronary syndrome in patients: results from a large prospective audit in Australia and New Zealand. Heart. 2014;100(16):1281-1288. doi:10.1136/heartjnl-2013-305296

2. Kumar A, Kar S, Fay WP. Thrombosis, physical activity, and acute coronary syndrome. J Appl Physiol. 2011;111(2):599-605. doi:10.11 52/japplphysiol.00017.2011

3. Aroney CN, Aylward P, Kelly AM, et al; Acute Coronary Syndrome Guidelines Working Group. Guidelines for the management of acute coronary syndromes. Med J Aust. 2006;184:S1-S32.
4. Jednacz E, Rutkowska-Sak L. Assessment of the body composition and parameters of the cardiovascular risk in juvenile idiopathic arthritis. Biomed Res Int. 2015;2015. doi:10.1155/2015/619023

5. Choudhury L, Marsh JD. Myocardial infarction in young patients. Am J Med. 1999;107(3):254-261. doi:10.1016/S0002-9343(99)00218-1

6. Egred M, Viswanathan G, Davis GK. Myocardial infarction in young adults. Postgrad Med J. 2005;81(962):741-745. doi:10.1136/pgmj.20 04.027532

7. Chouhan L, Hajar HA, Pompisiello JC. Comparison of thrombolytic therapy for acute myocardial infarction in patients aged $<35$ and $>55$ years. Am J Cardiol. 1993;71:157-159. doi:10.1016/0002-9149(93) 90731-q

8. Wolfe MW, Vacek JL. Myocardial infarction in the young. Angiographic features and risk factor analysis of patients with myocardial infarction at or before the age of 35 years. Chest. 1988;94 (5):926-930. doi:10.1378/chest.94.5.926

9. Thomas D. Athérosclérose [Atherosclerosis]. In: Cardiologie [Cardiology]. Paris: Ellipses; 1994:135-151. French.

10. Joussein-Remacle S, Delarche N, Bader H, Bader H, Lasserre R, Estrade G. Facteurs de risque de l'infarctus du myocarde du sujet jeune: registre prospectif sur un an [Risk factors in a young population with acute myocardial infarction: one year prospective study]. Ann Cardiol Angeiol. 2006;55:204-209. French. doi:10.1016/j. ancard.2006.05.001

11. Capolaghi B, Charbonnier B, Dumonet M, et al. Recommandations sur la prescription, le dosage et l'interprétation des troponines cardiaques [Recommendations on the prescription, dosage and interpretation of cardiac troponins]. Ann Biol Clin. 2005;63:245-261. French.

12. Piro M, Della Bona R, Abbate A, Biasucci LM, Crea F. Sex-related differences in myocardial remodeling. $J$ Am Coll Cardiol. 2010;55 (11):1057-1065. doi:10.1016/j.jacc.2009.09.065

13. Al-khadra AH. Clinical profile of young patients with acute myocardial infarction in Saudi Arabia. Int $J$ Cardiol. 2003;91(1):9-13. doi:10.1016/S0167-5273(02)00579-X

14. Nemetz PN, Roger VL, Ransom JE, Bailey KR, Edwards WD, Leibson CL. Recent trends in the prevalence of coronary disease: a population-based autopsy study of non-natural deaths. Arch Intern Med. 2008;168(3):264-270. doi:10.1001/archinternmed.2007.79

15. Tungsubutra W, Tresukosol D, Buddhari W, et al. Acute coronary syndrome in young adults: the Thai ACS registry. J Med Assoc Thai. 2007;90 Suppl 1(1):81-90.

16. Tuzcu EM, Kapadia SR, Tutar E, et al. High prevalence of coronary atherosclerosis in asymptomatic teenagers and young adults: evidence from intravascular ultrasound. Circulation. 2001;103(22): 2705-2710. doi:10.1161/01.CIR.103.22.2705

17. Al-Nozha MM, Arafah MR, Al-Mazrou YY, et al. Coronary artery disease in Saudi Arabia. Saudi Med J. 2004;25(9):1165-1171.

18. Battisha A, Sawalha K, Madoukh B, et al. Acute myocardial infarction in systemic mastocytosis: case report with literature review on the role of inflammatory process in acute coronary syndrome. Curr Cardiol Rev. 2021;16(4):333-337. doi:10.2174/1573403X16666200331123242

19. Singh A, Gupta A, Collins BL, et al. Familial hypercholesterolemia among young adults with myocardial infarction. $\mathrm{J} \mathrm{Am} \mathrm{Coll} \mathrm{Cardiol.}$ 2019;73(19):2439-2450. doi:10.1016/j.jacc.2019.02.059

20. Patel JV, Dwivedi S, Hughes EA, Gregory YH. Premature coronary artery disease: an inferred cardiovascular variant or a South Asian genetic disorder? Thromb Haemost. 2008;99:991-992. doi:10.1160/ TH08-05-0286

21. Chua SK, Hung HF, Shyu KG, et al. Acute ST-elevation myocardial infarction in young patients: 15 years of experience in a single center. Clin Cardiol. 2010;33(3):140-148. doi:10.1002/clc.20718

22. Teo KK, Ounpuu S, Hawken S, et al. INTERHEART Study investigators tobacco use and risk of myocardial infarction in 52 countries in the INTERHEART study: a case-young non-MS patients study. Lancet. 2006;368(9536):647-658. doi:10.1016/S0140-6736(06)69249-0 
23. Huang J, Qian HY, Li ZZ, Zhang JM. Comparison of clinical features and outcomes of patients with acute myocardial infarction younger than 35 years with those older than 65 years. $\mathrm{Am}$ $J$ Med Sci. 2013;346(1):52-55. doi:10.1097/MAJ.0b013e3182 $65 \mathrm{e} 33 \mathrm{e}$

24. Scheuner MT, Whitworth WC, McGruder H, Yoon PW, Khoury MJ. Familial risk assessment for early-onset coronary heart disease. Gen Med. 2006;8(8):525-531.

25. Ambrose JA, Barua RS. The pathophysiology of cigarette smoking and cardiovascular disease, an update. J Am Coll Cardiol. 2004;43 (10):1731-1737. doi:10.1016/j.jacc.2003.12.047

26. Bakhru A, Erlinger TP. Smoking cessation and cardiovascular disease risk factors: results from the third national health and nutrition examination survey. PLoS Med. 2005;2(6):528-535. doi:10.1371/ journal.pmed.0020160

27. Leone A. Relationship between cigarette smoking and other coronary risk factors in atherosclerosis: risk of cardiovascular disease and preventive measures. Department of internal medicine, City Hospital Massa, Carrara, Italy. Curr Pharm Des. 2003;9 (29):2417-2423. doi:10.2174/1381612033453802
28. Benacerraf A, Castilloy-Fennoy A, Goffinet D, Krantz D. L'infarctus du myocarde avant 36 ans: à propos de 20 cas [Myocardial infarction before age 36: about 20 cases]. Arch Mal Coeur. 1978;77 (7):756-764. French.

29. Collet JP, Zeitouni M, Procopi N, et al. Long-term evolution of premature coronary artery disease. J Am Coll Cardiol. 2019;74 (15):1868-1878. doi:10.1016/j.jacc.2019.08.1002

30. Kanitz MG, Giovannucci SJ, Jones JS, Mott M. Myocardial infarction in young adults: risk factors and clinical features. Emerg Med J. 1996;14:139-145. doi:10.1016/0736-4679(95)02089-6

31. Fan G, Fu K, Jin C, et al. A medical costs study of older patients with acute myocardial infarction and metabolic syndrome in hospital. Clin Interv Aging. 2015;10:329-337. doi:10.2147/CIA.S70372

32. Yang J, Biery DW, Singh A, et al. Risk factors and outcomes of very young adults who experience myocardial infarction: the partners YOUNG-MI registry. Am J Med. 2020;133(5):605-612. doi:10. 1016/j.amjmed.2019.10.020

33. Arbel Y, Havakuk O, Halkin A, et al. Relation of metabolic syndrome with long-term mortality in acute and stable coronary disease. Am J Cardiol. 2015;115(3):283-287. doi:10.1016/j.amjcard.2014.10.037
Journal of Blood Medicine

\section{Publish your work in this journal}

The Journal of Blood Medicine is an international, peer-reviewed, open access, online journal publishing laboratory, experimental and clinical aspects of all aspect pertaining to blood based medicine including but not limited to: Transfusion Medicine; Blood collection, Donor issues, Transmittable diseases, and Blood banking logistics; Immunohematology; Artificial and alternative blood based therapeutics; Hematology; Biotechnology/nanotechnology of blood related medicine; Legal aspects of blood medicine; Historical perspectives. The manuscript management system is completely online and includes a very quick and fair peer-review system. Visit http://www.dovepress.com/testimonials.php to read real quotes from published authors. 